Revista de Economia Política, vol. 40, nº 4, pp. 604-621, outubro-dezembro/2020

\title{
Financiamento da Covid-19, inflação e restrição fiscal
}

\author{
Financing COVID-19, inflation and fiscal constraint
}

LUIZ CARLOS BRESSER-PEREIRA*,**

RESUMO: A pandemia do Covid-19 está produzindo uma depressão econômica que poderia ser substancialmente reduzida se o Estado em cada país, além de fazer os gastos necessários na saúde, compensasse as empresas e famílias que estão perdendo com as políticas de distanciamento social e confinamento. Os governos, no entanto, limitam seus gastos para não aumentar a dívida pública. Mas existe a possibilidade de os bancos centrais comprarem novos títulos dos tesouros dos próprios países para financiar tais gastos. Considerando as várias restrições econômicas enfrentadas pelos formuladores de políticas, essa política não entrará em conflito com a restrição de inflação. O dinheiro é uma variável endógena que não causa, mas apenas sanciona a inflação em curso. O financiamento monetário entra parcialmente em conflito com a restrição fiscal, mas evita o aumento da dívida pública. E não traz as más consequências da indisciplina fiscal - demanda excessiva que, sucessivamente, causa aumento das importações e déficits em conta-corrente que apreciam a moeda nacional, aceleração ou inflação e crises de balanço de pagamentos. O financiamento monetário do Covid-19 não causará nenhum desses três males.

PALAVRAS-CHAVE: Gastos públicos; financiamento monetário; restrição de inflação; restrição fiscal.

ABSTRACT: The COVID-19 pandemic is producing an economic depression that could be substantially reduced if the state in each country, besides making the required health spending, compensates the companies and households that are losing with the social distance and lockdown policies. Governments limit their expenditures to not increase the public debt. There is, however, the possibility of the central banks buying new securities from the respective treasury to finance such exceptional expending. Considering the several economic constraints that policymakers face, this policy will not conflict with the inflation constraint. Money is an endogenous variable that does not cause, but just validates a going inflation. It conflicts partially with the fiscal constraint but avoids the increase of the public debt. And in this case there are no bad consequences of fiscal indiscipline - excess demand that, successively, causes increase in imports and current account deficits that, successively,

\footnotetext{
* Professor emérito da Fundação Getulio Vargas, São Paulo/SP, Brasil. E-mail: bresserpereira@gmail.com. Orcid: http://orcid.org/0000-0001-8679/0557. Submetido: 25/Março/2020; Aprovado: 2/Abril/2020.

* Uma versão em inglês deste artigo está sendo publicada simultaneamente no jornal Forum for Social Economics.
} 
appreciate the national currency, accelerate inflation, and lead to currency crises. Monetary financing of the COVID-19 will not cause any of these three evils.

KEYWORDS: Government spending; monetary financing; inflation constraint; fiscal constraint.

JEL Classification: E3; E6.

A pandemia de Covid-19 está produzindo uma crise econômica que pode se tornar maior que a Grande Depressão da década de 1930. Sua severidade pode ser avaliada pelo número de mortes, queda de produção, queda nas receitas dos Estados-nação e aumento do desemprego e da pobreza, mas variará de país para país, dependendo de quanto os Estados gastem para enfrentá-lo, e quão bem eles gastem. $\mathrm{O}$ achatamento da curva de novos casos e a redução do número de óbitos exigem o aumento da capacidade do sistema de saúde e a realização de políticas de distanciamento social e quarentena que, combinadas com testes em massa e rastreamento dos infectados, permitirão sua redução enquanto não é encontrada uma vacina ou um medicamento eficaz. Essas ações têm um custo para as empresas e para o Estado. Para as empresas porque serão obrigadas a limitar suas atividades. Para o Estado porque precisará aumentar seus gastos em saúde, que são relativamente pequenos, mas são altos quando o problema é neutralizar as perdas econômicas que a pandemia está causando: a queda do PIB, falências de empresas, desemprego, fome entre os mais pobres e queda das receitas tributárias. Até que ponto cada governo deve promover as quarentenas, não obstante a pressão das empresas para que o Estado as suspenda? E quanto o Estado deverá aumentar seus gastos para reduzir essas perdas ou custos econômicos dos fechamentos ou paralisações? Ninguém sabe ao certo quais são os custos e os benefícios, mas duas coisas são certas: primeiro, o Estado, não obstante a pressão das empresas, deve fechar de forma radical a economia e acompanhar o fechamento com o rastreamento dos infectados, porque, assim, estancará a difusão do vírus; segundo, quanto mais o governo gastar de maneira contracíclica, garantindo uma renda mínima para as pessoas e subsidiando as empresas que não demitiram seus funcionários, menor será a depressão que o país enfrentará. Mas o governo enfrenta uma restrição fiscal que o obriga a limitar o déficit público e a dívida pública. Por isso, para que essas duas medidas sejam satisfatórias o financiamento desses gastos extraordinários será realizado por emissão de moeda. Se o país tiver uma condição fiscal muito sólida, é provável que seu governo gaste o necessário de qualquer maneira. Vejam o caso da Alemanha, por exemplo. E será, também, capaz de resistir à pressão das empresas para que haja a abertura da economia. Na maioria dos casos, no entanto, os países não gastarão o necessário e resistirão mal às empresas.

Neste artigo, meu objetivo é discutir esta questão em quatro seções. Na primeira seção, focarei na variedade de resultados que os países estão alcançando e a sua relação com os gastos do governo. Na segunda, discutirei como financiar esses gastos. Financiamento privado ou "financiamento monetário", a emissão de moeda pelo Estado? E argumentarei a favor da segunda opção. Na seção seguinte, discuto 
as restrições econômicas que os governos enfrentam, particularmente a restrição de inflação, e argumentarei que o financiamento monetário não causará inflação. Finalmente, na quarta seção, reafirmo a importância da restrição fiscal, que é especialmente relevante se a associarmos à restrição cambial. Do ponto de vista da teoria novo-desenvolvimentista, argumentarei que antes que os gastos do governo causem inflação (porque a economia alcançou o pleno emprego), poderá causar o aumento das importações acima das exportações, o aumento do déficit em conta-corrente e a consequente apreciação da taxa de câmbio. No entanto, observo que a restrição fiscal não pode ser definida apenas se o déficit público estiver equilibrado; a dívida pública também faz parte da restrição fiscal. Ela deve ser mantida sob controle. No caso do financiamento da Covid-19, porém, além de as respectivas despesas serem excepcionais, o financiamento privado levará a um aumento enorme da dívida pública dos países, enquanto o financiamento monetário manterá essa dívida controlada.

\section{RESULTADOS DIFERENTES}

Com que eficácia os países estão controlando a propagação do vírus? A China, onde a pandemia começou em dezembro de 2019, realizou um bloqueio muito eficaz, controlou a propagação da doença, de modo que as mortes em meados de maio totalizavam apenas 4.634, enquanto nos Estados Unidos, que tem uma população um quarto menor, as mortes já totalizavam 109.448, e espera-se um aumento consideravelmente maior porque a difusão do vírus começou lá mais tarde do que na China. O fator de difusão (o número médio de pessoas infectadas por alguém com a doença) está caindo nos países ricos da Europa. Está abaixo de 1,10 na Alemanha, França, Itália e Espanha, e ainda em 1,23, mas caindo, nos Estados Unidos e no Reino Unido. Está sob controle na Turquia, Vietnã e Argentina, enquanto ainda está alto no Brasil $(1,45)$ e na Rússia $(1,79)$. Tais resultados estão relacionados às políticas de quarentena adotadas pelos países e ao seu cumprimento responsável pelas pessoas. Nos Estados Unidos, o resultado foi ruim e no Brasil, pior, enquanto seus respectivos presidentes resistiram a agir. No Brasil, cujo presidente dificultou o trabalho dos governadores estaduais e dos prefeitos de impor distância social, o número de mortos já é de 33.688 (maio 2020), enquanto na Argentina, cujo presidente adotou uma política de defesa firme contra a Covid-19, só temos 588 mortes. Os resultados negativos nos maiores países da Europa também são terríveis - Reino Unido e Itália com mais de 33 mil mortes, Espanha e França com mais de 29 mil mortes, enquanto Portugal, Dinamarca e Alemanha apresentam melhores resultados. ${ }^{1}$

Há muitas perguntas sendo feitas. Quantos ciclos haverá? Quanto tempo durará a pandemia? Por que a China controlou o vírus muito melhor do que os países

\footnotetext{
${ }^{1}$ Esta informação é do site worldtermometers.info, 2.5.2020.
} 
ocidentais? A resposta imediata que ouvi para essa última indagação é que este é um regime autoritário. É indubitavelmente autoritário, mas a democracia deve ser responsabilizada pelos maus resultados no Ocidente? Dinamarca, Nova Zelândia e Argentina são países cujo regime político é democrático, mas também controlaram a disseminação do coronavírus. E, em menor grau, também a Alemanha. Talvez uma explicação melhor seja que nos países em que o individualismo neoliberal foi longe, onde a lógica principal é a da concorrência de todos contra todos, como é o caso dos Estados Unidos e do Brasil, os resultados se mostraram piores.

Nos últimos 40 anos, no âmbito do neoliberalismo, o individualismo tornou-se hegemônico, "the only game in town", enquanto a ideia de solidariedade perdeu terreno. Uma sociedade em que isso acontece é uma sociedade doente. Quando uma pandemia como essa acontece, vemos quão importante é o Estado; fica claro que ele é nosso grande instrumento de ação coletiva. Vemos que se formos capazes de construir uma verdadeira nação, uma sociedade saudável, poderemos contar com um Estado caracterizado por leis sensatas, boas políticas, e tendo um aparato estatal capaz para aplicá-las. Nas sociedades capitalistas modernas o Estado pode ser um mero instrumento da classe dominante, mas, no quadro da democracia, pode contribuir para a construção de um sistema de solidariedade. Os países ricos avançaram nessa direção nos Anos Dourados do capitalismo, mas, desde os anos 1980, a ideologia neoliberal se tornou dominante e a regressão social e moral foi enorme, enquanto suas economias cresciam lentamente. A China não é uma democracia, mas essa pandemia mostrou que lá há mais solidariedade do que na maioria dos países ocidentais.

Como será o mundo depois dessa crise? Abandonará o neoliberalismo? De fato, o neoliberalismo foi abandonado desde a crise financeira global de 2008. Mas em países como os Estados Unidos e o Reino Unido, onde o individualismo se destacou, em vez de ser substituído por um capitalismo social, desenvolvimentista e ambiental, que é a alternativa real ao neoliberalismo, está sendo substituído pelo populismo nacionalista de direita, onde solidariedade e racionalidade estão ausentes. Algo semelhante mas mais grave acontece no Brasil. Em reação a 12 anos de governo de centro-esquerda (algo que nunca havia acontecido antes neste país), suas elites se tornaram radicalmente neoliberais e apoiaram o infame governo Bolsonaro, um governo de extrema direita. Apoiaram-no simplesmente porque antes da eleição ele escolheu para seu ministro da Economia um economista neoliberal. Brincaram de aprendizes de feiticeiro. Entre os males associados a esse governo está um desempenho desastroso em relação à pandemia. Como disse Francisco Lopes (2020), que acompanha de perto a difusão da Covid-19, o Brasil é um erro: "O Brasil está no caminho de se tornar um dos países infectados em um mundo que está convergindo para a estabilidade". ${ }^{2}$ Um verdadeiro genocídio está

\footnotetext{
${ }^{2}$ Os dados deste parágrafo se referem a 4 de junho de 2020; a fonte é Worldmeter e Francisco Lopes (2020).
} 
ocorrendo aqui devido aos obstáculos que o governo federal impõe ao isolamento das pessoas.

\section{COMO FINANCIAR?}

Qual será o custo econômico dessa crise? O FMI previu uma queda no PIB mundial de $5 \%$, mas acredito que será maior. E, em todos os países, os economistas estão prevendo um grande aumento na dívida pública. Existem duas maneiras de financiar os altos gastos públicos exigidos: emitindo títulos do tesouro e vendendo-os ao setor privado ou vendendo-os ao banco central. A primeira alternativa é um sistema usual e envolve o aumento da dívida pública; o segundo significa o governo "imprimir dinheiro", uma alternativa que leva as pessoas a tremer, porque isso significaria aumento da inflação e permitiria que o Estado gaste sem restrições. No entanto, o aumento da oferta monetária não causará inflação, dado o caráter excepcional da pandemia e a importância de se gastar o que é necessário para neutralizá-la, e, desde que seja bem regulamentada, a emissão de moeda não é incompatível com a restrição fiscal. Defendo, portanto, a segunda alternativa. A primeira, ao aumentar a dívida pública, obrigará os cidadãos, especialmente os mais pobres, a pagá-la através de inúmeras políticas de ajuste fiscal. Por outro lado, um grande aumento da dívida pública pode levar os países menos desenvolvidos a não serem capazes de pagá-la e serem forçados a pedir uma reestruturação desmoralizante de seus débitos. É verdade que o pagamento da dívida pública pode não ser tão oneroso se o governo conseguir manter a taxa de juros abaixo do crescimento do PIB, mas esse esforço forçará o país a adotar austeridade fiscal, sem ter garantia que logrará manter baixa a taxa de juros, e, assim, a sofrer baixas taxas de crescimento por muitos anos. O Reino Unido teve essa experiência: após a Primeira Guerra Mundial, sua dívida aumentou para $140 \%$ do PIB, levando o governo a se engajar em uma política de austeridade fiscal que levou a um alto superávit primário durante a década de 1920. Como observou o The Economist, os resultados foram desastrosos. A austeridade diminuiu o crescimento: a produção em 1928 permaneceu abaixo da produção de 1918, enquanto a dívida pública continuou a subir para $170 \%$ do PIB em 1930.3 Após a Segunda Guerra Mundial, o Reino Unido reduziu sua dívida pública de 259\% em 1946 para 43\% do PIB na década de 1980, mas sua taxa de crescimento no período foi substancialmente mais baixa que as taxas de crescimento da França, Alemanha e Itália. Os Estados Unidos também reduziram sua dívida pública de 112 para $26 \%$ do PIB nesse mesmo período, mas o fizeram mantendo uma taxa de crescimento satisfatória - o que era possível então porque este país experimentou um enorme crescimento com a guerra.

Essa é uma crise muito séria que afeta principalmente as minorias sociais e os mais pobres. O desafio de curto prazo que os governos enfrentam é fazer os gastos

\footnotetext{
${ }^{3}$ The Economist, "How deep will downturns in rich countries be?”, 16.4.2020.
} 
necessários. A possibilidade de financiar as despesas da Covid-19 sem aumentar a dívida pública é importante para todas as classes sociais e todos os tipos de países. Se os formuladores de políticas souberem que ao emitir dinheiro a dívida pública não aumentará nem causará inflação, eles terão mais liberdade para gastar o que é realmente necessário, em vez de gastar “o que puderem”. Se eles insistem em não acreditar que isso é possível, ou se são formuladores de políticas nos países da Zona do Euro que não têm o poder de emitir moeda, é provável que gastem menos do que o necessário. Ainda não existem dados definitivos sobre quanto os grandes países estão gastando para enfrentar a Covid-19, mas já existem bons estudos. Segundo o Instituto Brasileiro de Economia da FGV (IBRE), existem grandes variações. Considerando apenas os programas governamentais, temos que alguns países, como Austrália, Canadá, e Japão, estão gastando muito (respectivamente, 10,1\%, 9,1\% e $6,8 \%$ do PIB), enquanto outros, como Itália, França e Espanha, estão gastando pouco (respectivamente, $1,2 \%, 2,0 \%$ e $2,7 \%$ do $\mathrm{PIB}$ ). ${ }^{4}$ Eu não creio que isso seja por acaso. Os países que gastam menos são exatamente os que cometeram o grande erro de criar o euro e perderam a autonomia da política monetária. Vimos isso muito claramente na crise do euro (2010-2015) e parece que estamos vendo isso novamente na crise da Covid-19. A Alemanha, neste estudo, é uma exceção, gastando $6 \%$ do PIB, mas sabemos como a conta fiscal do país é gerenciada com extremo rigor visando enormes superávits em conta-corrente e uma indústria competitiva. Sabemos, também, quão competente é sua primeira-ministra, Angela Merkel.

Após a crise financeira global de 2008, os bancos centrais dos países ricos se envolveram em flexibilização quantitativa (quantitative easing). Os objetivos eram aumentar a oferta de dinheiro ou a liquidez do sistema econômico, reduzir as taxas de juros e incentivar as empresas a investir. O último objetivo não foi atingido, mas uma quarta consequência, não intencional, foi uma grande diminuição da dívida pública dos países que a praticavam. No caso do Japão, cuja dívida era imensa, a redução causada pela flexibilização quantitativa foi enorme: o Banco Central do Japão detém hoje $85 \%$ da chamada "dívida pública" do país, o que significa que ela foi reduzida em $77 \%$; a redução da dívida pública dos Estados Unidos foi menor, $12 \%$, e esse pode ser o motivo pelo qual os economistas americanos não prestaram muita atenção ao fato. ${ }^{5}$

Mas o financiamento monetário não implica aumento da dívida pública? Não é isso que vemos ao examinar a evolução da "dívida pública” dos países que realizaram flexibilização quantitativa. As dívidas públicas do Japão, Estados Unidos, Reino Unido, Suíça, Suécia e dos países da Zona do Euro não foram adequadamente ajustadas. $\mathrm{O}$ fato de o tesouro e o banco central fazerem parte de um mesmo Estado não foi considerado porque os economistas adoram ficções; porque desejam desencorajar "gastos públicos irresponsáveis" e porque as regras de contabilidade

\footnotetext{
${ }^{4}$ Fonte: Laboratório de Política Fiscal do IBRE / FGV. Dados de 26.4.2020.

${ }^{5}$ Meu cálculo é baseado nas informações bem fundamentadas de Kate Allen e Keith Fray (2017)

“Central banks hold a fifth of their governments' debt”, Financial Times, 15.8. 2017.
} 
pública continuam sendo regidas por conceitos ultrapassados; essas regras não consideram o banco central como parte do Estado, algo que só foi verdade no início da história dos bancos centrais quando os bancos privados assumiram alguns dos papéis que hoje têm os bancos centrais.

Economistas ortodoxos rejeitam o financiamento monetário; para eles, a única alternativa para financiar gastos estatais que não são cobertos pelas receitas correntes é ficar endividado com o setor privado. Eles dizem que os custos da Covid-19 serão altos, mas "não há mágica" - após a pandemia os países terão que retomar a austeridade fiscal para pagar a dívida pública aumentada. Existem boas razões para a disciplina fiscal, mas, a financiar as despesas da Covid-19, o financiamento monetário faz mais sentido. Foi o que os países ricos fizeram após a crise de 2008, adotando uma flexibilização quantitativa. E é o que alguns deles estão fazendo novamente, embora não digam, para financiar os gastos associados à pandemia. No caso de flexibilização quantitativa, a compra de títulos públicos e privados foi feita com o objetivo de aumentar a liquidez das economias nacionais, mas a compra de títulos públicos teve a consequência, talvez inesperada, de reduzir a dívida pública. Digo "talvez" porque é difícil acreditar que no Japão, onde a dívida pública original era imensa e o alívio quantitativo era igualmente imenso, os japoneses não tinham consciência de que estavam reduzindo sua dívida. No caso atual, além de aumentar a liquidez, essa compra deve ter como objetivo não reduzir a dívida pública, como ocorreu com a experiência quantitativa de flexibilização, mas financiar despesas com a Covid-19 sem aumentar essa dívida. Segundo as projeções do FMI, no final deste ano a dívida pública do mundo rico deve aumentar de $106 \%$ para $122 \%$ do PIB. Em relação ao Brasil, a previsão geralmente feita é de um aumento de $78 \%$ para $95 \%$ do PIB. Em qualquer circunstância, os enormes gastos estatais necessários para a queda das receitas dos Estados significarão grandes déficits fiscais e, se o financiamento monetário não for adotado, um aumento considerável da dívida pública além de, após a crise, anos e anos pagando essa dívida.

\section{RESTRIÇÕES ECONÔMICAS}

Minha defesa do financiamento monetário das despesas relacionadas à Covid-19 coloca duas questões imediatas. Esse financiamento monetário não causaria inflação? Pior, você está sugerindo que o Estado pode gastar o quanto os governos quiserem? Começo pela segunda pergunta. Não estou dizendo que as restrições econômicas, incluindo a restrição fiscal, devam ser ignoradas. Para ser um formulador de políticas competente, um economista deve estar ciente das restrições que enfrenta. Mas a restrição fiscal não é a única restrição econômica nem a principal. Nesta seção, discutirei em breve as principais restrições econômicas que os países enfrentam, e particularmente a restrição de inflação. E argumentarei que, no presente caso, essa restrição não será violada. Na próxima seção, discutirei apenas a restrição fiscal.

A taxa esperada de lucro. Uma série de restrições define um sistema econômi- 
co capitalista. Os economistas políticos clássicos e particularmente Marx conheciam a principal delas: a restrição econômica abrangente é a taxa de lucro, ou, mais precisamente, a taxa de lucro empresarial esperada - a taxa de lucro esperada menos o custo do capital. A taxa de crescimento depende de investimentos que, por sua vez, dependem da motivação das empresas para investir, a qual, finalmente, depende de uma taxa de lucro esperada satisfatória. O crescimento econômico é um processo histórico de acumulação de capital com incorporação de progresso técnico ou aumento de produtividade associado à melhoria dos padrões de vida um processo no qual o Estado e as empresas estatais respondem por uma parcela do investimento total. No início do processo de crescimento, essa participação costuma ser alta, porque os principais investimentos necessários estão na infraestrutura e no setor de insumos básicos, e porque o Estado tem mais acesso ao crédito do que os empresários. Mas, à medida que a economia se desenvolve, o setor privado se fortalece financeiramente, enquanto o crescimento exige inovações em novos produtos e novos serviços, e todo o sistema econômico se torna cada vez mais sofisticado. A partir deste momento, o investimento depende da criatividade e capacidade gerencial dos empreendedores, cujas iniciativas apenas o sistema de mercado é capaz de validar e coordenar com eficiência. Assim, o setor privado vê sua participação no investimento total aumentar para cerca de $80 \%$, sob a condição, naturalmente, de que a taxa de lucro esperada seja satisfatória - capaz de motivar as empresas a investir.

Assim, em uma sociedade capitalista, o lucro é a primeira e principal restrição. $\mathrm{Na}$ verdade, é uma restrição que define o capitalismo. A taxa de lucro não precisa ser "alta", mas não pode ser "baixa"; deve ser satisfatória - um conceito que tomo de Herbert Simon. Se tivéssemos que dar uma breve definição do capitalismo, diríamos que é o modo de produção em que os empresários acumulam capital, com o objetivo de obter lucro. O lucro máximo? Em princípio, sim, mas esse é um conceito sem sentido em termos de negócios; as empresas conhecem as restrições do mercado e não visam um lucro máximo vago, mas o lucro possível que elas projetam em seus orçamentos. Qual é uma taxa de lucro satisfatória no intervalo que as empresas consideram suficiente para continuar investindo e expandindo a produção em um determinado país e tempo? É a taxa mínima de lucro que motiva as empresas a investir. A taxa de lucro satisfatória é uma convenção ou instituição historicamente localizada. É superior à taxa de lucro "normal" da microeconomia; também é superior à taxa de lucro da empresa que para de inovar e apenas investe na modernização da fábrica e continua produzindo bens e serviços cuja demanda deixou de se expandir. É uma taxa de lucro "razoável".

A restrição salarial. A restrição salarial é definida de duas maneiras; do lado da oferta, em quanto os salários podem aumentar, mantendo-se consistentes com uma taxa de lucro satisfatória; do lado da demanda, quanto eles podem não aumentar sem causar uma queda na demanda. Nos dois casos, a restrição está subordinada à restrição de lucro - a uma taxa de lucro satisfatória. Do lado da oferta, considerando estável a relação produção-capital, esse limite é o aumento da produtividade do trabalho. $\mathrm{Na}$ época dos economistas políticos clássicos, a restrição 
salarial era "física" porque a suposição era de que o custo de reprodução do trabalho, definido como nível de subsistência, definia a taxa salarial. Hoje, é uma restrição relativa, porque os salários continuam a ser basicamente determinados pelo custo de reprodução do trabalho, mas esse custo é socialmente definido e aumenta à medida que o nível de educação e aquisição de capacidades profissionais aumenta. Assim, como estão acima do nível de subsistência nos países ricos, os salários podem aumentar ou diminuir. Desde a virada neoliberal de 1980 até hoje, os salários de trabalhadores não qualificados permaneceram estagnados ou aumentaram menos que a produtividade, enquanto os altos salários aumentaram fortemente e a taxa de lucro das empresas permaneceu relativamente satisfatória para os gerentes e acionistas. A nova competição representada pelos países em desenvolvimento exportadores de manufaturados, iniciada na década de 1970, é uma das causas da quase estagnação dos baixos salários; outra foi a aceleração do progresso técnico e o aumento do tamanho das grandes corporações, que aumentaram a demanda pela crescente classe social tecnoburocrática e reduziram a demanda por trabalhadores pouco qualificados. Ambas as causas estão do lado da oferta. E o lado da demanda? Os salários que cresceram abaixo da produtividade diminuíram a demanda por bens de consumo que precisavam ser compensados por alguma coisa. A principal estratégia era aumentar o crédito para as classes mais baixas, o que manteve a demanda relativamente forte, mas foi uma das principais causas da crise financeira global de 2008. O retorno à economia neoclássica e a ascensão da ideologia neoliberal foram fundamentais para legitimar a quase estagnação dos baixos salários e o aumento da desigualdade que caracterizou o período.

A restrição de demanda. Alguns podem argumentar que um mercado com bom comportamento garante automaticamente uma taxa de lucro satisfatória. Mas isso não é verdade, teoricamente ou empiricamente. Do lado teórico, Schumpeter argumentou definitivamente que a concorrência perfeita e o correspondente fluxo normal de bens e serviços apenas produzem "lucros normais", que são essencialmente iguais à taxa de juros. Os empresários exigem uma taxa de lucro mais alta, que somente as inovações podem garantir - inovações que geram uma vantagem monopolista. Keynes, partindo de uma perspectiva diferente, revolucionou a economia quando mostrou que, nas economias capitalistas, a oferta não assegura automaticamente a demanda, como fazem o clássico e o neoclássico, mas sofre de uma insuficiência crônica de demanda que diminui a taxa de lucro esperada por longos períodos, tornando os investimentos pouco atraentes ou apenas inviáveis. No sistema de restrições econômicas que estou tentando descrever, a demanda efetiva - a disposição e a capacidade dos consumidores de comprar mercadorias - é nossa segunda principal restrição econômica. A literatura econômica sobre essa restrição é enorme. Sua verificação empírica, mais do que satisfatória. Não há nada a acrescentar a essa literatura, exceto a questão do acesso à demanda, mas esse problema faz parte da restrição seguinte - a restrição da taxa de câmbio.

A taxa de câmbio ou restrição de competitividade. Além do argumento keynesiano sobre a insuficiência da demanda, há uma segunda razão teórica pela qual a taxa de lucro esperada nem sempre é satisfatória. Como o Novo Desenvolvimentis- 
mo vem discutindo a partir da década de 2000, muitos países podem viver com uma taxa de câmbio sobrevalorizada no longo prazo, combinada com um ciclo de taxa de câmbio definido por uma forte desvalorização nas sucessivas crises cambiais e uma taxa de câmbio apreciada entre elas. Esse fato abre espaço para uma terceira restrição econômica - a restrição da taxa de câmbio. A taxa de câmbio deve tornar as empresas monetariamente e tecnicamente competitivas - nacional e internacionalmente - mas muitas vezes isso não acontece. Quando uma empresa utiliza a melhor tecnologia disponível, é tecnicamente competitiva; quando, além disso, a taxa de câmbio é competitiva intertemporalmente e os "custos do país", ou seja, os custos tributários e de infraestrutura, são semelhantes aos dos países concorrentes, essa empresa é economicamente competitiva. A ideia de que o formulador de políticas pode ignorar o problema da taxa de câmbio para incentivar as empresas a aumentar sua competitividade técnica é frequentemente ouvida, mas não faz sentido.

Por que a taxa de câmbio mostra a tendência de ser sobrevalorizada no longo prazo? Nos países em desenvolvimento, exceto os países do Leste Asiático, há uma razão básica: a adoção de duas políticas habituais - a política de crescimento com endividamento externo e a política de âncora cambial para controlar a inflação. As duas políticas implicam déficits em conta-corrente e exigem altas taxas de juros para atrair os capitais necessários para financiar esses déficits. A política de crescimento com endividamento externo, baseada na expectativa de que os bens financiados sejam bens de capitais, é autoderrotante, porque as entradas de capitais necessárias para financiar o déficit tornam não competitivas as empresas capazes do país e as desencorajam a investir, enquanto incentivam o consumo. A segunda política habitual - transformar a taxa de câmbio em uma âncora monetária para controlar a inflação - também envolve sobrevalorização e, portanto, é tão autodestrutiva quanto a primeira política habitual. É verdade que os fluxos de capital são altamente especulativos, mas no curto prazo; no longo prazo, assumindo reservas internacionais constantes, os fluxos líquidos de capital serão iguais aos déficits e representarão uma oferta extra de moeda estrangeira que valorizará a moeda do país. Essas entradas de capital adicionais manterão a moeda nacional apreciada enquanto o déficit em conta-corrente for mantido. Algo que pode durar muito tempo, porque os formuladores de políticas locais argumentam que "estamos adotando a política de crescimento com poupança externa", e porque desde o Consenso de Washington passaram a contar com o apoio das agências internacionais. Os argumentos derivam de algo que parece óbvio ("é natural que países ricos em capital transfiram seus capitais para países pobres em capital”), mas são essencialmente equivocados. Seriam verdadeiros se vivêssemos em um Estado global em que haveria uma moeda única e as taxas de câmbio desapareceriam. Ou se, por alguma mágica, o excesso de entradas de capitais sobre as saídas não causasse a valorização da moeda do país destinatário.

Em relação aos países ricos, a taxa de câmbio combinada com déficit em conta-corrente também representa uma grande restrição importante. A famosa exceção são os Estados Unidos, que emitem a moeda-reserva dominante e, consequentemente, se beneficiam de o "privilégio exorbitante" de poder ter um elevado déficit em conta- 
-corrente sem risco de quebrar. Esse país se beneficia desse privilégio desde a década de 1960. Mas também para ele a restrição existe, não sob a forma de crises cambiais (isso é impossível), mas sob a forma de sobrevalorização de longo prazo do dólar e perda de competitividade da indústria manufatureira norte-americana.

No quadro da globalização, a competitividade é hoje uma restrição fundamental que associo à restrição da taxa de câmbio. Existe uma competitividade técnica e macroeconômica ou cambial. A microeconomia cuida da competitividade técnica; a macroeconomia deve cuidar da competitividade da taxa de câmbio. Ambas são condições necessárias para o desenvolvimento econômico, mas nem sempre estão juntas. A competitividade técnica é um problema econômico de longo prazo, a competitividade cambial é um problema de curto prazo. Boas instituições, mercados que funcionam bem, educação, investimento em infraestrutura, política tecnológica e política industrial são meios para a competitividade técnica. Uma política macroeconômica capaz vê a restrição cambial como fundamental, na medida em que é o único meio de garantir a competitividade da taxa de câmbio. Tentar alcançar a competitividade macroeconômica agindo nas variáveis microeconômicas, tornando os mercados mais competitivos, como defendem os economistas ortodoxos, ou adotando políticas industriais, como muitos economistas heterodoxos propõem, é um grande erro. Existe uma relação entre as duas competitividades, mas elas são relativamente autônomas e exigem políticas independentes.

A restrição da taxa de câmbio não deve ser confundida com a "restrição da balança de pagamentos". Raúl Prebisch usou a lei de Engel, ${ }^{6}$ o problema das duas elasticidades-renda menores que uma, para mostrar a desvantagem competitiva que os países exportadores de bens primários enfrentavam, e argumentar em favor de seu projeto de industrialização ou, em espanhol, "cambio estructural”. Hollis Chenery foi o primeiro a fazer uma interpretação equivocada desse problema com o modelo de dois hiatos que seria "resolvido" com a entrada de capitais estrangeiros. ${ }^{7}$ O segundo foi Anthony Thirlwall, que formalizou elegantemente o modelo das duas elasticidades-renda perversas, abrindo espaço para inúmeros estudos econométricos que confirmavam o que era óbvio. ${ }^{8}$ No entanto, a "lei de Thirlwall", além de favorecer a entrada de capital, permitiu um "modelo de crescimento" no qual o crescimento do comércio exterior global limitaria a taxa de crescimento do país - algo muito distante da experiência de poucos países que, no século XX, fizeram o catch-up com sucesso e hoje são países ricos. A restrição real da balança de pagamentos nos países em desenvolvimento não são as elasticidades perversas, mas a tendência à sobrevalorização da taxa de câmbio, que não é endógena ao sistema econômico, mas causada por políticas econômicas equivocadas.

\footnotetext{
${ }^{6}$ A lei de Engel afirma que, à medida que a renda aumenta, a proporção da renda gasta em alimentos cai mesmo que o gasto absoluto em alimentos aumente. É nomeada de acordo com seu formulador, o estatístico alemão Ernest Engel.

${ }^{7}$ Chenery e Bruno (1962).

${ }^{8}$ Thirlwall (1979).
} 
A restrição de inflação. Uma quarta grande restrição econômica é a restrição de inflação. Não há nada novo sobre esse tema desde o modelo de inflação inercial do início dos anos 1980, mas, como estou defendendo o financiamento monetário da Covid-19, é hora de discutir se o aumento da oferta de moeda acima do aumento da oferta agregada causa inflação; segundo, se a impressão de dinheiro faz diferença, independentemente do financiamento privado ou do financiamento monetário (o banco central ou o setor privado compra os novos títulos emitidos pelo tesouro de cada país), o aumento dos gastos do governo envolve o aumento da quantidade de dinheiro. Nos dois casos ocorre o mesmo aumento no crédito pendente e, portanto, na oferta de moeda, que varia de acordo com o volume de crédito. Se o governo decidir pelo financiamento privado, onde o setor privado encontrará recursos para comprar os títulos oferecidos pelo governo? O capitalista rentista não tem dinheiro disponível e irá ao setor financeiro para pedir dinheiro emprestado. Assim, a oferta monetária aumentará de qualquer maneira.

O aumento da oferta monetária não é a causa da inflação, aqui entendida "causa" como um fator que acelera uma determinada taxa de inflação. Primeiro, porque a oferta monetária é endógena, como afirma a teoria keynesiana, bem como a teoria monetária moderna (MMT) e a teoria do novo desenvolvimento (TND). No tempo de Keynes, isso não era tão óbvio, porque então o padrão-ouro ainda não havia sido abandonado e o dinheiro ainda era, aparentemente, um dinheiro-mercadoria. Desde 1971, quando o governo norte-americano removeu o último vestígio do padrão-ouro encerrando a conversibilidade do dólar em ouro (o que era garantido apenas a outros países, não ao setor privado), o caráter virtual ou de confiança do dinheiro ficou evidente. As variações na quantidade de dinheiro em uma economia são uma variável endógena. O banco central pode influenciá-lo, mas não o determinar, comprando títulos emitidos pelo tesouro, definindo a taxa de reserva que os bancos precisam emprestar, reduzindo ou aumentando a taxa de juros, mas a quantidade de dinheiro depende dos gastos do governo e de mudanças no volume total de crédito. Essa é a razão pela qual o papel da oferta monetária no processo de inflação não causará ou acelerará a inflação, mas sancionará ou validará a inflação vigente, garantindo, por meio do aumento do crédito, que a liquidez real (e necessária) seja mantida.

No entanto, existe um antigo medo das pessoas de que o financiamento monetário do Estado cause inflação. E há a teoria quantitativa do dinheiro que apoiou essa ideia - um mito econômico antigo e desgastado. Que, provavelmente, se originou desde os tempos antigos, quando a inflação era chamada não de aumento de preços, mas de aumento descontrolado da quantidade de dinheiro na economia. ${ }^{9}$ Esse mito foi ressuscitado pelo monetarismo, a primeira tentativa que economistas neoclássicos fizeram de desenvolver uma alternativa à macroeconomia keynesiana

\footnotetext{
${ }^{9}$ De acordo com o Online Etymological Dictionary, a inflação, no "sentido monetário de 'aumento dos preços' (originalmente por um aumento na quantidade de dinheiro em circulação) foi registrada pela primeira vez em 1838 no inglês americano". Cf. https://www.etymonline.com/word/inflation, 6.6.2019.
} 
em que a oferta agregada, e não a demanda agregada, era a variável relevante. A alegação básica do monetarismo era que, se os bancos centrais controlassem firmemente a oferta de moeda, a inflação seria controlada. $\mathrm{Na}$ literatura econômica existe uma identidade, a equação de troca $(M V=Y p)$, na qual $M$ é a quantidade de dinheiro, $V$ é a velocidade da moeda ou o número de vezes que a moeda circula em um ano, Y é a renda nacional e p, a inflação. É uma identidade porque parte da definição da velocidade de circulação da moeda $(\mathrm{V}=\mathrm{Yp} / \mathrm{M})$. Os monetaristas, no entanto, transformaram essa identidade em uma teoria - a teoria quantitativa assumindo que a velocidade da moeda é constante e afirmando que o aumento de $M$ causa o aumento da inflação, $p$.

Aparentemente, essa teoria é verdadeira porque existe uma estreita correlação entre a quantidade de moeda e a inflação, mas, primeiro, $V$ não é constante, a velocidade da moeda é extremamente variável, mudando com o ciclo econômico. ${ }^{10}$ Segundo, não há razão para dizer que é o aumento em M que causa o aumento em p; faz mais sentido dizer que é o aumento da inflação que exige que a oferta monetária nominal aumente. Uma economia nacional precisa de um nível de liquidez ou quantidade de dinheiro proporcional ao seu PIB para funcionar - para permitir que as transações ocorram sem problemas. Quando, por algum motivo, a inflação aumenta ou acelera, a oferta nominal de moeda precisa aumentar para que a quantidade real de moeda - a liquidez da economia - seja preservada. Para entender isso, ajuda visualizar a liquidez monetária necessária do sistema com a quantidade de óleo lubrificante que permite que a máquina funcione sem problemas, sem atrito. Assim, a quantidade nominal de dinheiro é endógena e, dada a quantidade real necessária de dinheiro, é a inflação que exige que seu aumento permaneça constante em termos reais. Keynes não disse isso literalmente, mas mostrou que a quantidade de dinheiro em uma economia é endógena. Aqui no Brasil, aprendi o caráter endógeno do dinheiro com Ignácio Rangel, que teve essa ideia observando a realidade brasileira do início dos anos 1960. ${ }^{11}$ Entre os pós-keynesianos, Basil Moore, em 1979, mostrou teoricamente a endogeneidade da moeda. ${ }^{12}$ A teoria da inflação inercial, na forma em que foi desenvolvida no Brasil (o país que teve a experiência mais longa e mais radical desse tipo de inflação), mostrou isso definitivamente no artigo de 1984 que definiu mais amplamente essa teoria e que afirma isso no próprio título, "Fatores aceleradores, mantenedores e sancionadores da inflação" ${ }^{13} \mathrm{O}$ fator acelerador da inflação pode ser um choque de oferta ou demanda, mas na

\footnotetext{
${ }^{10}$ Nos Estados Unidos, na Grande Depressão, chegou a 1,15 vez. Desde 1959 até o final de 2007, a velocidade do estoque monetário foi em média 1,86 vez, com um máximo de 2,21 vezes em 1997 e um mínimo de 1,66 vez em 1964. Desde 2007, a velocidade do dinheiro caiu drasticamente à medida que o Federal Reserve expandiu bastante seu balanço, ou seja, envolvido em flexibilização quantitativa; no primeiro trimestre de 2016, a velocidade M2 foi de apenas 1,46 vez.

${ }^{11}$ Ignácio Rangel (1963).

12 Basil J. Moore (1979).

${ }^{13}$ Bresser-Pereira e Yoshiaki Nakano (1984 [1987]): 5-21.
} 
maioria dos casos e logicamente é o excesso de demanda em relação à oferta; a indexação formal e informal dos preços é o fator inercial ou de manutenção, o que torna a inflação resistente às políticas usuais adotadas para controlá-la; e a indexação formal e informal da economia é o fator sancionador que mantém constante a quantidade real de moeda em um ambiente em que a inflação está reduzindo a quantidade nominal de moeda. ${ }^{14}$ Quanto à rejeição empírica do monetarismo, a flexibilização quantitativa demonstrou definitivamente que o monetarismo não faz sentido. Os bancos centrais dos países ricos compraram diretamente do tesouro e do setor privado cerca de US\$ 15 trilhões sem aumentar a taxa de inflação.

Por que, então, a teoria quantitativa do dinheiro tem uma história tão longa? Primeiro, porque é aparentemente verdade. Segundo, porque o aumento da oferta monetária é determinante da inflação por uma razão etimológica: originalmente a palavra "inflação" significava simplesmente o aumento da quantidade de dinheiro em circulação. ${ }^{15} \mathrm{O}$ poder de uma tradição etimológica é forte. Terceiro, um raciocínio da economia política: inflação acima de $3 \%$ ou $4 \%$ ao ano é ruim para todos, mas especialmente ruim para os capitalistas rentistas e os financiadores; é pior para eles do que para os capitalistas produtivos cujos preços podem ser alterados com a inflação. Assim, eles apoiam qualquer política que pareça difícil contra a inflação, mesmo que ela não funcione ou funcione mal.

\section{A RESTRIÇÃO FISCAL}

Encerro a análise das restrições econômicas e da Covid-19 com a restrição fiscal. Meu entendimento é que essa é a restrição principal e que o financiamento dos gastos governamentais exigidos com a emissão de dinheiro não sinalizará indiferença, mas respeito a ela na medida em que será uma maneira de proteger a condição fiscal de cada país que a utiliza.

A restrição fiscal é óbvia e a mais conhecida. Geralmente, os bons ministros das finanças têm como dever diário proteger o tesouro dos rent-seekers (dos capturadores do patrimônio público) e manter o orçamento fiscal equilibrado. E é algo que a história econômica confirma. Os países que obtiveram sucesso em termos econômicos e hoje os países ricos observaram disciplina fiscal, como o Reino Unido, a França e os Estados Unidos, que realizaram sua revolução industrial e capitalista no século XIX, ou aqueles como o Japão e a Coreia do Sul, que fizeram isso no século XX. Talvez considerando esse fato, mas provavelmente devido ao

\footnotetext{
${ }^{14}$ É por isso que, em seu artigo básico sobre essa teoria, Bresser e Nakano (1984 [1987]) chamaram a oferta de moeda de "fator sancionador da inflação".

15 A inflação é originária do latim "inflatio", que significava "sopro", "flatulência”, "inflamação". De acordo com o Online Etymological Dictionary, inflação significando "ação de inflar com ar ou gás” é do século XVII; o "sentido monetário de 'aumento de preços' (originalmente por um aumento na quantidade de dinheiro em circulação) foi registrado pela primeira vez em 1838 no inglês americano".
} 
seu método hipotético-dedutivo que dispensa verificação empírica, os economistas ortodoxos defendem que uma política fiscal austera definida dessa maneira (um orçamento equilibrado) é a única política legítima.

Por que isso seria verdade? O argumento tradicional é assim: se a disciplina fiscal for observada, o mercado cuidará do resto; caso contrário, o Estado gastará mais do que aquilo que arrecadará, incorrerá em déficit fiscal, financiando o déficit com dívida crescente, a oferta de moeda aumentará e a inflação seguirá. Isso é falso porque o mercado não cuida do resto e porque o aumento da oferta de moeda não causa inflação. A ortodoxia liberal oferece duas razões adicionais. Primeiro, esse investimento público excluirá o investimento privado. Mas isso depende da indústria em que o Estado investe. Se o Estado investe nos mesmos setores competitivos que o setor privado, a exclusão será inevitável. Por outro lado, se investir em infraestrutura e em setores de insumos básicos, os dois setores não competitivos para os quais o investimento público deve ser orientado, criará demanda e promoverá o investimento privado nas empresas que fornecem bens e serviços para esses dois setores. Segundo, seria necessária disciplina fiscal "porque o Estado pode ir à falência" essa explicação não faz sentido. Um Estado-nação não é uma empresa; se estiver endividado em sua própria moeda, nunca irá à falência porque sempre pode emitir dinheiro e pagar suas dívidas; se estiver endividado em moeda estrangeira, o problema é mais sério, mas a teoria novo-desenvolvimentista é inflexível ao condenar que os países e seus governos se endividem em moeda estrangeira. Somente quando a economia está crescendo muito rapidamente as oportunidades de investimento aumentam e a propensão marginal a consumir cai enquanto a propensão marginal a investir aumenta - somente nessas condições excepcionais que o endividamento externo não se transforma em consumo e, sim, em investimento.

Vamos agora examinar razões melhores para os governos limitarem seus gastos. Um primeiro motivo, conhecido e bom, é a inflação. Se o governo aumentar seus gastos e a demanda agregada do país exceder a oferta a inflação se acelerará e os gastos terão que ser reconsiderados. No entanto, esse não é o caso dos gastos necessários da Covid-19; não há qualquer pressão de demanda. Uma segunda e mais geral razão pela qual os gastos do governo devem ser cuidadosa e firmemente controlados é que realmente "não há almoço grátis", mas há rent-seeking grátis. A ganância em relação aos gastos do governo é sempre enorme, porque é gratuita. De qualquer forma, mesmo quando é necessário aumentar os gastos públicos, como é o caso presente, os formuladores de políticas econômicas competentes têm como um de seus principais papéis a defesa do tesouro do Estado. No momento em que relaxamos a disciplina fiscal, o contrato social - que exige que todos cumpram as leis e que estejam razoavelmente comprometidos com o interesse público - também é relaxado, e aumenta a probabilidade de gastos incorretos e corrupção.

A terceira razão envolve a combinação da taxa de câmbio e a restrição fiscal: os governos devem adotar disciplina fiscal para evitar que o aumento da demanda cause déficit em conta-corrente e valorização da moeda nacional. Nesse caso, os irresponsáveis gastos do governo ainda não começaram a causar inflação, porque o país recorre a importações adicionais e incorre em déficit em conta-corrente, mas a apreciação da moeda nacional já está ocorrendo. Esse terceiro motivo deriva da teoria 
novo-desenvolvimentista, onde a restrição da taxa de câmbio, que também poderíamos chamar de restrição da conta-corrente, desempenha um papel fundamental.

Portanto, os gastos excessivos do governo, que desconsideram a restrição fiscal, criarão sucessivamente três males: primeiro, o aumento do déficit em conta-corrente e a valorização da moeda nacional; segundo, o aumento da inflação; e terceiro, a crise cambial. A história econômica dos países que se desenvolveram de forma consistente é também uma história de disciplina fiscal. Não porque a generosidade fiscal leva o país à falência, nem porque o investimento público impede o investimento privado, mas porque bons políticos e formuladores de políticas competentes combinam teoria (que é sempre incapaz de considerar todas as possibilidades) e intuição para tomar suas decisões. Eles sabem que a disciplina fiscal é parte do contrato social que cada nação exige para a construção de uma sociedade boa e desenvolvida. Um contrato social que pode e deve conter um projeto de desenvolvimento nacional para que o país cresça rapidamente e realize o catch-up. Ao causar déficit em conta-corrente e valorização da moeda nacional, a indisciplina fiscal prejudica seriamente a competitividade monetária do país, causa inflação e, no limite, o acúmulo de déficits em conta-corrente aumenta a dívida externa do país e pode levar o país a uma crise cambial. $\mathrm{Na}$ verdade, a disciplina fiscal e o controle da conta-corrente caminham juntas. Se o aumento das despesas fiscais aumenta a demanda efetiva acima da oferta doméstica, isso não leva à inflação, a menos que a economia esteja em pleno emprego, mas causa um déficit em conta-corrente que é um fator negativo no processo de crescimento. Temos, então, os "déficits gêmeos" e taxa de câmbio sobrevalorizada. Quando isso acontece e tanto o déficit em conta-corrente quanto o deficit público se tornam altos, o governo não tem condições de baixar os juros para depreciar a moeda, e é levado a realizar ajuste fiscal para recuperar sua competitividade. Mas essa é uma política custosa (envolve recessão e desemprego).

Assim, voltamos à restrição cambial, agora não porque o governo do país esteja engajado na política equivocada de crescimento com endividamento externo (que equivale a populismo cambial), mas porque está gastando irresponsavelmente mais do que aquilo que arrecada - o que configura o populismo fiscal. Ou porque os dois processos populistas, fiscal e cambial, se reforçam. ${ }^{16}$ Em síntese, a razão fundamental pela qual os países devem manter sua conta fiscal equilibrada é a restrição da taxa de câmbio - é manter o país competitivo internacionalmente. As empresas devem ser competitivas tecnicamente, mas, além disso, o país deve garantir uma taxa de câmbio que permaneça competitiva. Os déficits em conta-corrente significam que o país é orientado para o consumo, e não orientado para a produção; significa que as pessoas valorizam o consumo imediato e não se preocupam com a acumulação de capital e o crescimento.

Portanto, existem boas razões para sustentar a restrição fiscal, mas como de-

\footnotetext{
${ }^{16} \mathrm{O}$ populismo econômico chegou para gastar de forma irresponsável; pode ser populismo fiscal, quando o Estado gasta mais do que aquilo que obtém e incorre em déficits fiscais crônicos, ou populismo cambial, quando o Estado-nação gasta mais do que aquilo que obtém e o país incorre em déficits crônicos em conta-corrente.
} 
fini-la? Consiste apenas em ter um orçamento equilibrado? Ou inclui, também, a manutenção da dívida pública sob controle e relativamente baixa? Não é hora de discutir essa questão, mas uma coisa é importante ressaltar: a dívida pública não é o resultado da simples acumulação de déficits públicos. Quando, por exemplo, o banco central socorre bancos em crise, o custo não é considerado no déficit. Os ganhos ou perdas do banco central decorrentes de variações na taxa de câmbio também não são considerados no déficit ou no superávit fiscal, mas estão na dívida pública. Em determinados momentos, sabemos que os déficits orçamentários contracíclicos são o caminho certo; eles não devem pôr em risco a saúde financeira do país. Agora, considerando as enormes e extraordinárias despesas exigidas pela Covid-19, qual política afeta mais a restrição fiscal: recorrer ao financiamento monetário e manter a dívida pública intocada ou recorrer ao financiamento privado e criar uma enorme carga fiscal para o futuro? Na segunda seção do artigo, eu já discuti os males associados ao aumento da dívida pública.

\section{CONCLUSÃO}

Em resumo, no contexto da pandemia de Covid-19, os países não devem limitar os gastos do governo em nome da restrição fiscal. Agora é mais importante salvar a vida das pessoas, seus empregos e a sobrevivência das empresas e, com esse objetivo em mente, não economizar - algo que os governos farão se considerarem que os enormes gastos necessários significarão um déficit público maior. Por esse motivo, e para evitar o peso de uma grande dívida pública no futuro próximo, defendo o financiamento monetário das despesas da Covid-19.

Para justificar isso, resumo brevemente minha visão sobre as restrições econômicas básicas nas sociedades capitalistas. Elas são a restrição de lucro, a restrição de demanda, a restrição da taxa de câmbio, a restrição salarial e a restrição fiscal. Primeiro, mostrei que o financiamento monetário dos altos gastos exigidos pela Covid-19 não causará inflação. Segundo, dei uma atenção especial à restrição fiscal e acrescentei uma nova e fundamental razão pela qual ela é uma restrição real (gastos excessivos, antes de atingir o pleno emprego e causar inflação, podem causar aumento das importações, déficits em conta-corrente e apreciação da moeda nacional). De fato, o financiamento monetário não envolverá déficits crônicos em conta-corrente, não envolverá flexibilização ou enfraquecimento do contrato social e evitará um grande aumento da dívida pública.

Ao defender as restrições fiscais e cambiais, não defendi a "austeridade fiscal" uma política ortodoxa de direita que economistas heterodoxos como eu criticam fortemente. Minha definição de austeridade é certamente mais restrita que a definição populista que a identifica com disciplina fiscal. A austeridade, para mim, é fazer duas coisas: primeiro, rejeitar a política de déficits fiscais contracíclicos e, segundo, quando a economia enfrenta não apenas inflação, mas também desequilíbrio externo, envolver-se apenas em ajustes fiscais como se o país fosse um economia fechada, em vez de usar as ferramentas macroeconômicas para depreciar a moeda nacional e, dessa maneira, distribuir os custos do ajuste entre os assalariados e os capitalistas rentistas. 
A Teoria Monetária Moderna, que também vê a oferta monetária como endógena e tem muito claro que um Estado-nação não pode ir à falência, deduz frequentemente dessa premissa correta que o Estado não enfrenta uma restrição fiscal. Como observa Warren Mosler, “o dinheiro fiduciário do governo significa necessariamente que os gastos públicos não precisam se basear na receita”. Randall Wray, por sua vez, em seu livro sobre a Teoria Monetária Moderna, afirma que "governos soberanos não precisam emprestar sua própria moeda para gastar”. Essas duas afirmações são apenas parcialmente verdadeiras e são perigosas. Elas abrem espaço para negar a restrição fiscal. Os economistas da TMM têm contribuído de maneira inovadora e séria para a crítica da austeridade fiscal neoclássica ou ortodoxa, mas o que Keynes já disse sobre esse assunto é suficiente. Duvido que mesmo políticos progressistas adotem seus pontos de vista sobre economia. Se não forem adotadas com cuidado, as políticas correspondentes podem facilmente causar perda de competitividade internacional, inflação e, com exceção dos Estados Unidos, crise cambial. Os políticos e formuladores de políticas capazes que levaram os países ricos de hoje a crescer e realizar o catch-up foram geralmente corajosos e inovadores, mas também eram economistas prudentes. Embora os chefes de governo possam, em determinadas circunstâncias como as atuais, recorrer ao financiamento monetário sem incorrer em riscos, devem estar profundamente convencidos disso. Bons políticos não estão dispostos a oferecer o cargo de ministro das Finanças a economistas que menosprezam a restrição fiscal.

\section{REFERÊNCIAS BIBLIOGRÁFICAS}

Allen, Kate e Keith Fray (2017) “Central banks hold a fifth of their governments' debt”, Financial Times, August 15 de 2017.

Bresser-Pereira, Luiz Carlos e Yoshiaki Nakano (1984) “Accelerating, maintaining, and sanctioning factors of inflation”, Brazilian Journal of Political Economy 4(1) January 1984: 5-21. In English, only in the online version of the journal.

Chenery, Hollys e Michael Bruno (1962) "Development alternatives in an open economy: The case of Israel”, Economic Journal, March 1962: 79-103.

Lopes, Francisco L. (2020) “Covid-19: o Brasil estabiliza até agosto?” Valor, 5 June.

Moore, Basil J. (1979) "The endogenous money stocks", Journal of Post Keynesian Economics, Autumn 1979, 2(1): 49-70.

Mosler, Warren (1996) Soft Currency Economics II. Christiansted: Valance Company.

Rangel, Ignácio M. (1963) A Inflação Brasileira. Rio de Janeiro: Tempo Brasileiro.

Thirlwall, Anthony P. (1979) "The balance of payments constraint as an explanation of international growth rates differences”, Banca Nazionale del Lavoro Quarterly Review 128: 45-53. https:// EconPapers.repec.org/RePEc:psl:bnlqrr:1979:01

Thirlwall, Anthony P. e M. Nureldin Hussain (1982) "The balance of payments constraint, capital flows and growth rates differences between developing countries", Oxford Economic Papers 34(3) November: 498-510.

Wray, L. Randall (2015) Modern Money Theory: A Primer on Macroeconomics for Sovereign Monetary. 2nd revised edition. London: Palgrave Macmillan. 